\title{
Anatomical studies on the atrioventricular valves of the ostrich heart (Struthio camelus)
}

\author{
M. A.M. Alsafy, S.A. El-Gendy, S. Enany and M. Amine \\ Anatomy and Embryology Department, Faculty of Veterinary Medicine, Alexandria \\ University, Edfina, Rashed, Behera, Egypt
}

With 8 Figures

Received May2009, accepted for publication August 2009

\begin{abstract}
Ostrich hearts of both sexes and aged 9-12 month were studied grossly by sagittal and transverse sections. The right atrioventricular orifice of ostrich heart was guarded by a single triangular muscular plate which acted with the bulged convex interventricular septum as the right atrioventricular valve. This plate was fixed to the parietal wall of the right ventricle by a muscular bundle and to the right side of interventricular septum by a membrane. There was a sac between the right ventricular parietal wall and the outer surface of the triangular muscular plate formed between the most cranial thick border of the right atrioventricular valve and the basal wall of the right ventricle. The left atrioventricular orifice was guarded by three cusps; septal, left cranioparietal and right caudoparietal. The septal cusp was somewhat triangular in outline while the left and right cranioparietal cusps were somewhat quadrilateral in shape. The left ventricle has three small papillary muscles and chordae tendinae which were classified into true and false chordae tendinae according to their point of insertion. The longitudinal trabeculae carneae were rosette-like
\end{abstract} in number toward the apex.

\section{Keywords}

Anatomy, Atrioventricular valves, Ostrich.

\section{Introduction}

The African ostrich is native to Africa and Arabian Desert areas (class Aves; order Struthio-niformes; family Struthionidae; genus Struthio). It is of high economic value, as its meat is tender, delicious and highly nutritious. Its leather is flexible, permeable and highly durable, making it one of the three topgrade leathers, the other two being crocodile skin and reindeer skin (Mushi et al., 1998; Deeming, 1999 and Wang et al., 2001). Hence, ostrich breeding is improving greatly recently, and researches about ostrich is also picking up. The available literature on the anatomy of the ostrich heart is scanty (Bezuidenhout 1984 and 1986 described the topography of the heart of ostrich and coronary vessels). The right atrioventricular valve is formed by a single muscular flap which acts as a valve with the interventricular septum 
(Kent, 1983 and Cayre et al., 1993) in chick. The right ventricle has no chordae tendinae and papillary muscles (Marshall and Hughes, 1980) in chick. The left atrioventricular valve is a tricuspid valve (King and Mclelland, 1984 and Dyce et al., 2002) in the chick. The tricuspid left atrioventricular valve has three cusps attached to the chordae tendinae in the duck (Rigdon and Frolich, 1970). In domestic birds the free border of this tricuspid valve carries a variable number of chordae tendinae which anchor at their ends to papillary muscles of the three cusps, one is located against the septum, the other two on the outer wall) (Nickel et al., 1977). In chickens, a number of chordae tendinae arises from the papillary muscles and attaches at the free edge of the cusps (Aydinlioglu and Ragebetlim, 1998). In addition, each cusp receives short chordae tendinae from the two adjacent papillary muscles. There are three short papillary muscles that project slightly to the lumen of the left ventricle) (Baumel, 1975).

In the present study, we aimed to describe the detailed anatomy of the right and left atrioventricular valves in the ostrich heart by sagittal and transverse sections.

\section{Materials and Methods}

Twelve hearts of ostriches of both sexes and aged 9-12 month collected from the slaughter house of Alexandria and Behera governorate in Egypt were used in the current study.

\section{Longitudinal sections of the heart}

Ten hearts were used to perform the longitudinal sections of the heart

1. To study the right atrioventricular valve and the cavity of the right ventricle of the heart, a longitudinal section was carried out on the left surface from the conus arteriosus through the right ventricular wall cranial to the left paraconal groove by about $1 \mathrm{~cm}$ from the apex of the heart (Fig1B).

The second longitudinal section was done on the right surface from the coronary groove through the right ventricular wall and cranial to the right subsinosal groove by about $1 \mathrm{~cm}$ from the apex of the heart (Fig1A).

2. To study the left atrioventricular valve and the cavity of the left ventricle of the heart,

A third longitudinal section was

carried out through the left ventricular border from the apex of the heart to the left atrium crossing the coronary groove (Fig1A).

3. To describe the different parts of the heart and their relation to each other, a sagittal section of the heart was done through the center of aortic orifice to the base of the heart (Fig1A).

\section{Cross sections of the heart.}

Two hearts were used to study the relationships between the heart parts. Seven transverse serial sections were done through the whole heart from the base of the heart to the apex $1 \mathrm{~cm}$ slice 
thickness interval (Fig1B) (Karkoura, 1989).

\section{Results}

\section{Right atrioventricular valve}

The right atrioventricular valve consisted of a single triangular muscular plate which acted with the bulged convex inter-ventricular septum (Fig.2/2) as the right atrioventricular valve (Fig.2/3, Fig.7/E/3). The traingular muscular plate extended along the lateral wall of the right ventricle and widened from the anterior to posterior commissure. The free edge of the triangular muscular plate (Fig.7/D/4) projected into the right ventricular cavity where its dorsal and lateral edges were continuous with the muscular wall of the right ventricle. The length of the free border of this muscular plate was about $8 \mathrm{~cm}$ while the attached border was $7.5 \mathrm{~cm}$. The width at the middle part of this muscular plate was about $4 \mathrm{~cm}$. It decreased toward the apex near the distal insertion in the parietal wall where it was about 3 $\mathrm{cm}$. The thickness of the attached border at the right atrioventricular orifice was about $0.8 \mathrm{~cm}$ and $0.5 \mathrm{~cm}$ near its distal insertion in the parietal wall while the free border was $0.3 \mathrm{~cm}$ and $0.4 \mathrm{~cm}$ near its distal insertion in the parietal wall.

The triangular muscular plate was fixed to the parietal wall of the right ventricle by a muscle bundle (Fig.2/5) called trabecular muscle which subdivided the triangular muscular plate into anterior and posterior-lateral regions. The trabecular muscle was about $1.5 \mathrm{~cm}$ in

J. Vet. Anat. length, $1 \mathrm{~cm}$ in width and $0.8 \mathrm{~cm}$ in thickness and it inserted into the triangular muscular plate directly without intermediation of chordae tendinae. The triangular muscular plate attached to the right side of the interventricular septum by a thin membrane which was about $3.1 \mathrm{~cm}$ in length, $1 \mathrm{~cm}$ in width and $1-2 \mathrm{~mm}$ in thickness (Fig.2/4).

Our study denoted a sac between the right ventricular parietal wall and the outer surface of the triangular muscular plate formed by the fusion between the most cranial thick border of the right atrio-ventricular valve and the basal wall of the right ventricle called the Cul-desac (Fig.2/7). This sac was connected with the conus arteriosus through a narrow semilunar opening (Fig.2/9) between the unattached part of the cranial border of the triangular muscular plate and the right ventricular parietal wall. The right ventricle contained a number of false chordae tendinae between the parietal and septal walls (Figs. 3/B, 7/C). However the middle part of right ventricle contained a number of false chordae tendinae between the outer wall of the triangular muscular plate and the parietal wall (peripheral wall of the cul-de-sac) (Figs. $2 / 6,7 / D$ ) while the basal part of the right ventricle was nearly free from the false chordae tendinae. The right ventricle was free from any true chordae tendinae.

In the transverse and sagittal sections, the triangular muscular plate partially divided the right ventricular cavity (Fig.7/E/3). The interventricular septum 
curved and bulged at the level of the triangular muscular plate thus facilitating the closing mechanism of the right atrioventricular orifice (Fig.7/D, E and Fig.8/5).

\section{Left atrioventricular valve}

The left atrioventricular valve was tricuspid and situated between the left atrium and the left ventricle. It consisted of fibrous ring, three cusps, three commissures, chordae tendinae and three papillary muscles (Fig.4, Fig.5and Fig. 6).

\subsection{Left atrioventricular fibrous ring}

The fibrous ring was completely surrounded the left atrioventricular orifice (Fig.5/12). Its circumference was about $11.5 \mathrm{~cm}$ through which the Left atrioventricular valve was attached.

2.2. Cusps of the Left atrioventricular valve

Left atrioventricular opening was guarded by three cusps (Fig. 5). The circumference of the valve free border was about $10 \mathrm{~cm}$ while the attached border was $11.5 \mathrm{~cm}$.

\subsubsection{Septal cusp}

It was somewhat triangular in outline. The length of the attached border was about $5 \mathrm{~cm}$ while the free border was $3.5 \mathrm{~cm}$. The length of septal cusp between the attached and free borders was about $1.2 \mathrm{~cm}$ (Fig. 4/1 and Fig. $5 / 7)$.

The chordae tendinae of the septal cusp were 5 pairs in number and each

J. Vet. Anat. one originated from the two adjacent papillary muscles (septal and septoparietal) and inserted into the free border of the cusp. The chordae tendinae were divided toward the ventricular aspect of the overlying cusp into primary, secondary and tertiary chordae tendinae. The strength of these chordae tendinae depends on the point of their attachment: the strongest chordae were those attached at the apex (Fig.4/13) while the weakest at the commissure (Fig.4/14), the chordae attached at the sides of the cusp were intermediate in position and strength.

\subsubsection{Left cranioparietal cusp}

The left cranioparietal cusp was somewhat quadrilateral in shape. The length of the cusp was about $1.1 \mathrm{~cm}$. The length of the attached border was about $3.5 \mathrm{~cm}$ while the length of the free border was about $3 \mathrm{~cm}$ (Fig. $4 / 3$ and Fig. 5/6). The chordae tendinae of this cusp were 4 pairs in number, each one originated from the two adjacent papillary muscles (parietal and septoparietal) and inserted into the free border of this cusp. The chordae tendinae were divided on the ventricular surface of the overlying cusp into primary, secondary and tertiary.

\subsubsection{Right caudoparietal cusp}

The right caudoparietal cusp was somewhat quadrilateral in shape. The length of the cusp was about $1.2 \mathrm{~cm}$. The length of the attached border was about $3 \mathrm{~cm}$, while the length of the free border was about $2.5 \mathrm{~cm}$ (Fig. 4/2 and Fig. 5/8). 
The chordae tendinae of this cusp were 4 pairs in number and each cusp originated from the two adjacent papillary muscles (septal and parietal) and inserted into the free border of the cusp. They were divided on the ventricular surface of the overlying cusp into primary, secondary and tertiary.

\subsection{Commissures}

The left atrioventricular valve has three commissures: left (caudal) (Fig.5/9) middle (septal) (Fig.5/10) and right (cranial) (Fig.5/11), which subdivided the mitral valve into three cusps (septal, left cranioparietal and right caudoparietal cusps). The chordae tendinae which attached to these commissures were fan-shaped. They were the weakest among the chordae tendinae (Fig.4/14).

\subsection{Chordae tendinae}

The chordae tendinae were classi-fied into true and false chordae tendinae according to their point of insertion.

\subsubsection{False chordae tendinae}

The left ventricle contained false chordae tendinae which originated and terminated at any point of the left ventricle other than the cusps or commissures and classified according to their position into six types:

a. Septopapillary chordae tendinae: they were two in number located between papillary muscles and septal wall.

J. Vet. Anat. b. Papillaromarginal chordae tendinae: they were five in number located between papillary muscles and parietal wall (Fig. 4/15 and Fig. 6/12).

c. Septomarginal chordae tendinae: they were seven in number located between septal wall and parietal wall (Fig. 4/7 and Fig. 6/10).

d. Intraseptal chordae tendinae: they were eight in number located between trabeculae carneae on septal wall and parietal wall (Fig.6/11).

e. Intraparietal chordae tendinae: they were 20-22 in number located between trabeculae carneae on parietal wall (Fig.6/B/13).

f. Intrapapillary chordae tendinae: they were three in number located between the papillary muscles.

The highest number of false chordae tendinae was located at the apical part of left ventricle. This number decreased moving toward the basal part of left ventricle. The false chordae tendinae were nearly correlated to the number of the trabeculae carneae which also increased in number toward the apical part of the left ventricle.

The right ventricle also had false chordae tendinae. These false chordae were found at the apical part of the right ventricle between the parietal and the septal wall (Fig.7/C) and in the middle part between the outer wall of the triangular muscular plate and the parietal wall (peripheral wall of the culde-sac) (Fig.2/6, Fig.3/6, Fig.7/D and 
Fig.8/15). The basal part of right ventricle was free from false chordae tendinae.

\subsubsection{True chordae tendinae}

The true chordae tendinae origina-ted from the papillary muscles and inserted into the cusps or commissures, so they were called papillary chordae tendinae. These chordae were located only in the left ventricle and were divided into three types. The right ventricle had not true chordae tendinae.

a. Chordae tendinae of the septal papillary muscle

They were 5 pairs in number and their length about 1.5-2 cm (Fig.4/5). The strongest true chordae tendinae were inserted near the apex of the cusps (Fig.4/13), the weakest ones at the commissures (Fig.4/14); those chordae which were inserted at the sides of the cusps were moderate in the strength.

b. Chordae tendinae of the parietal papillary muscle

They were 4 pairs in number and their length about 1-1.5 cm and were shorter than that of the septal papillary muscle.

c. Chordae tendinae of the septoparietal papillary muscle

They were 5 pairs in number and their length about $0.8-1 \mathrm{~cm}$ and were the shortest true chordae tendinae.

\section{Trabeculae carneae}

The longitudinal trabeculae carneae appeared in the cross section as

J. Vet. Anat. rosette-like or wedged shaped structures. They increased in number moving toward the apex of the left ventricle. The basal third of the left ventricle and the aortic vestibule have not trabeculae carneae while the middle third have seven trabeculae carneae. The highest numbers, fifteen, of trabeculae carneae were present at the apical third of the left ventricle. The longest trabeculae carneae were present at the septal wall and were about $8.5 \mathrm{~cm}$ in length. The thickest trabeculae carneae were present at the middle third of the left ventricle. These trabeculae became thinner moving toward the apical third. They were higher in number than in the middle third of the left ventricle. The mural wall of the left ventricle had a higher number of trabeculae carneae than the septal wall which has, in turn, the longest trabeculae. The direction of the trabeculae carneae was parallel to the long axis of the heart (Fig.4/11, Fig.6/6 and Fig.8/14).

\subsection{Papillary muscles}

The left ventricle had three small papillary muscles

\section{a. Septal papillary muscle}

It was triangular in shape and was about $3 \mathrm{~cm}$ in length, $0.9 \mathrm{~cm}$ in diameter; $1 \mathrm{~cm}$ in width, $0.6 \mathrm{~cm}$ in thickness and its circumference was about $3.2 \mathrm{~cm}$ (Fig.4/5, Fig.5/2 and Fig.8/21). Its longitudinal axis was almost parallel to the long axis of the left ventricle and situated distal to the middle commissure (Fig.5/10). The

Vol 2 No1, (2009) 67 - 83 
septal papillary muscle had five pairs of true chordae tendinae to the septal and right caudoparietal cusp and one false chorda tendina.

\section{b. Parietal papillary muscle}

It was quadrilateral in shape and was about $2.8 \mathrm{~cm}$ in length, $0.7 \mathrm{~cm}$ in diameter; $1.8 \mathrm{~cm}$ in width, $0.5 \mathrm{~cm}$ in thickness and their circumference was about $3 \mathrm{~cm}$ (Fig.4/6, Fig.5/3 and Fig.8/20). It was situated at the same level of the septoparietal papillary muscle ventral to the right commissure (Fig.5/11). The parietal papillary muscle had four pairs of true chordae tendinae and two false chordae tendinae. The distance between the septal and parietal papillary muscle was about 5 $\mathrm{cm}$. That between the parietal and the septoparietal papillary muscle was about $1-1.5 \mathrm{~cm}$.

c. Septoparietal papillary muscle (dorsal)

It was the smallest papillary muscle and was quadrilateral in shape. It was about $2.8 \mathrm{~cm}$ in length, $0.6 \mathrm{~cm}$ in diameter, $1 \mathrm{~cm}$ in width, $0.4 \mathrm{~cm}$ in thickness and its circumference was about $2.8 \mathrm{~cm}$ (Fig.4/4, Fig.5/1 and Fig.8/13). The distance between the septal and septoparietal papillary muscle was about $2.5 \mathrm{~cm}$. This papillary muscle had 4 pairs of true chordae tendinae and one false chorda tendina.

\section{Discussion}

In the current study the right atrioventricular valve was formed by a single triangular muscular plate which acts with the bulged convex interventricular septum as the right atrioventricular valve. This finding was similar to that observed by Cayre et al. (1993) and Aydinlioglu and Ragebetlim (1998) in the chick heart. The triangular muscular plate was extended along the lateral wall of the right ventricle, its free edge was projected into the right ventricular cavity and its dorsal and lateral edges were continuous with the muscular wall of the right ventricle. These observations were similar to those obtained by Chiasson (1992) in the pigeon.

The left atrioventricular orifice was guarded by the left atrio-ventricular valve which was composed of septal, left cranioparietal, and right caudoparietal cusps. This is in agreement with that denoted by Rigdon and Frolich (1970) in the duck and Koch and Rossa (1973) in the chicken. Left ventricle had three small papillary muscles which were situated in the parietal wall (parietal papillary muscle), in the septum (septal papillary muscle) and in both the parietal wall and septum (septoparietal papillary muscle). Of the three membra-nous cusps, one was situated in the septum (septal cusp); the other two were situated in the parietal wall (left cranioparietal and right caudoparietal cusp). These results agree with those obtained in the chicken by Baumel (1975) and in the duck by Rigdon and Frolich (1970). Each cusp received chordae tendinae from the two adjacent papillary muscles. In addition, the right septal cusp appeared as the largest cusp of the 
tricuspid valve. Similar findings were observed by Baumel (1975) in Gallus.

Left atrioventricular orifice was surrounded completely by a fibrous ring which was thick as observed by Aydinlioglu and Ragebetlim (1998) in chick. The left ventricle had) longitudinal trabeculae carneae which appeared in cross section as rosette-like or wedged shaped structures and increased in number toward the apex of the left ventricle. Our results showed that the architecture of Chordae tendinae, Trabeculae carneae and papillary muscles of the ostrich heart are very similar to that described by Baumel (1975) and Dyce et al. (2002) in the chicken.

\section{References}

Aydinlioglu, A. and Ragebetlim, C. (1998): A morphological study in the broiler chick hearts. Folia Morphol (warsz). 57: 4: 357-62

Baumel ,J.J. ( 1975): The anatomy of the Aves (Heart and Blood vessels). In: Sisson and Gross-man's the anatomy of the domestic animals, Vol. II. Fifth edition. W.B. Saunders Company, Philadelphia, London, Toronto.

Bezuidenhout, A.J. (1984)): The coronary circulation of the heart of the ostrich (Struthio camelus).Journal of Anatomy. 138: 385-397

Bezuidenhout, A.J. ( 1986): The topography of the thoracoabdominal viscera in the ostrich
(Struthio Camelus). Onderstepoort Journal of Veterinary Research. 53: 111-117

Cayre, R., Valencia-Mayoral, P., Coffe-Ramirez,V.,Angelini, P., Sanchez-Gomez, C., and dela cruz, M.V. (1993): The Right Atrio-ventricular Valvular Apparatus in the Chick Heart. Acta Anatomica. 148: 27 - 33

Chiasson, B.R. (1992): Laboratory Anatomy of the Pigeon, third edition. Tucson, Arizona.

Deeming, D.C. (1999): The Ostrich Biology, Production and Health Hatchery Consulting and Research, Wallingford, Oxon, UK.

Dyce, K.M., Sack, W.O. and Wensing, C.J.G. (2002): Text book of Veterinary anatomy. W.B. Saunders Company, Philadelphia, London, Toronto.

Karkoura, A.A. (1989): Some anatomical studies on the heart of one humped Camel. Ph.D.Thesis Faculty of Veterinary Medicine Alexandria University.

Kent, C.G. (1983): Comparative Anatomy of the Vertebrates, Fifth edition. Mosby Company, Louisiana, London, Toronto.

King, A.S. and Mclelland ,J. (1984): Birds, their Structure and Function, second edition. Baillière Tindall, London.

Koch, T. and Rossa, E. (1973): Anatomy of the Chicken and Domestic Birds, edited and translated from German by; 
Bernard H. Skold, Louis

Devries. Lowa State

University Press Ames, lowa.

Marshall, P.T. and Hughes, G.M.

(1980): Physiology of Mammals and other vertebrate, Second edition.Cambridge,London, New York, New Rochelle, Melbourne, Sydney.

Mushi, E.Z., Isaj, J.F., Chabo,

R.G. and Segaise, T.T. (1998): Growth rate of ostrich (Struthio camelus) chicks under intensive management in Botswana. Tropical Animal Health Production. 30: 197-203
Nickel, R., Schummer, A. and Seiferle, E. (1977): Anatomy of the Domestic Birds, translated by W.G. Siller and P.A.L. Wight, Verlag Paul Parey, Berlin, Hamburg.

Rigdon, R.H. and Frolich, J. (1970): The heart of the duck. Zentralblatt für veterinär medizin. 17: 85-94

Wang, X.C., Zhang, M.X. and Min, H.P. (2001): Histological structure of artificial breeding ostrich skin. China. Leather. 3: 350-38 


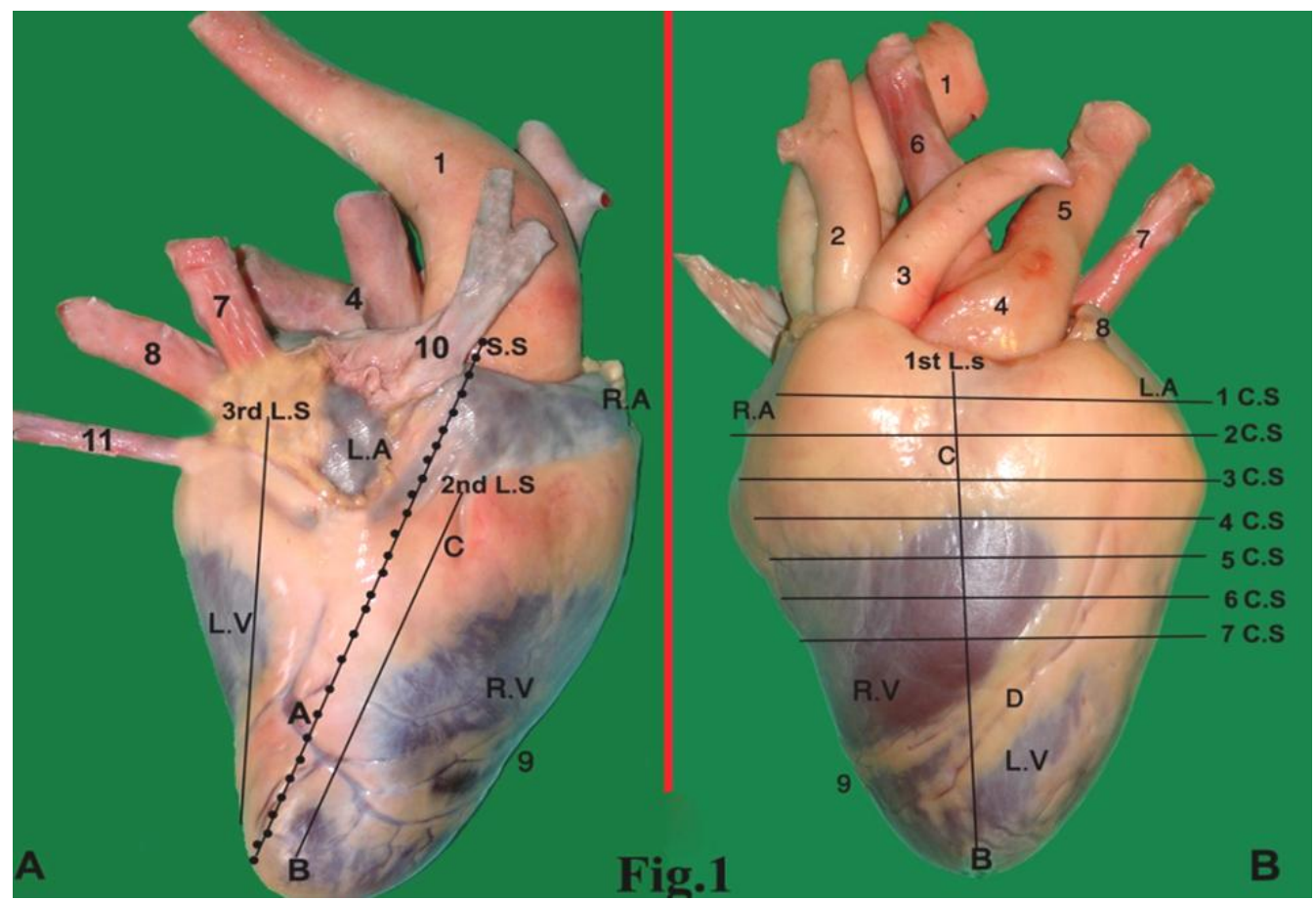

Figure (1): The level of longitudinal, sagittal and cross sections. A Right surface of the ostrich heart, B Left surface of the ostrich heart.

1 Aorta, 2 Right brachiocephalic artery, 3 Left brachiocephalic artery, 4 Pulmonary trunk, 5 Right pulmonary artery, 6 Left pulmonary artery, 7 Right cranial vena cava, 8 Caudal vena cava, 9 Incisura apices, 10 Pulmonary vein, 11 Left cranial vena cava.

A Right longitudinal subsinosal groove, B Apex of the heart, C Coronary groove, D Left longitudinal paraconal groove. L.A. Left atrium, R.A. Right atrium, L.V. Left ventricle, R.V. Right ventricle. $1^{\text {st }}$ L.S. indicates the first longitudinal section, $2^{\text {nd }}$ L.S. indicates the second longitudinal section, $3^{\text {rd }}$ L.S. indicates the third longitudinal section, S.S. Dotted line indicates the sagittal section, 1-7 C.S. indicates the level of cross sections. 


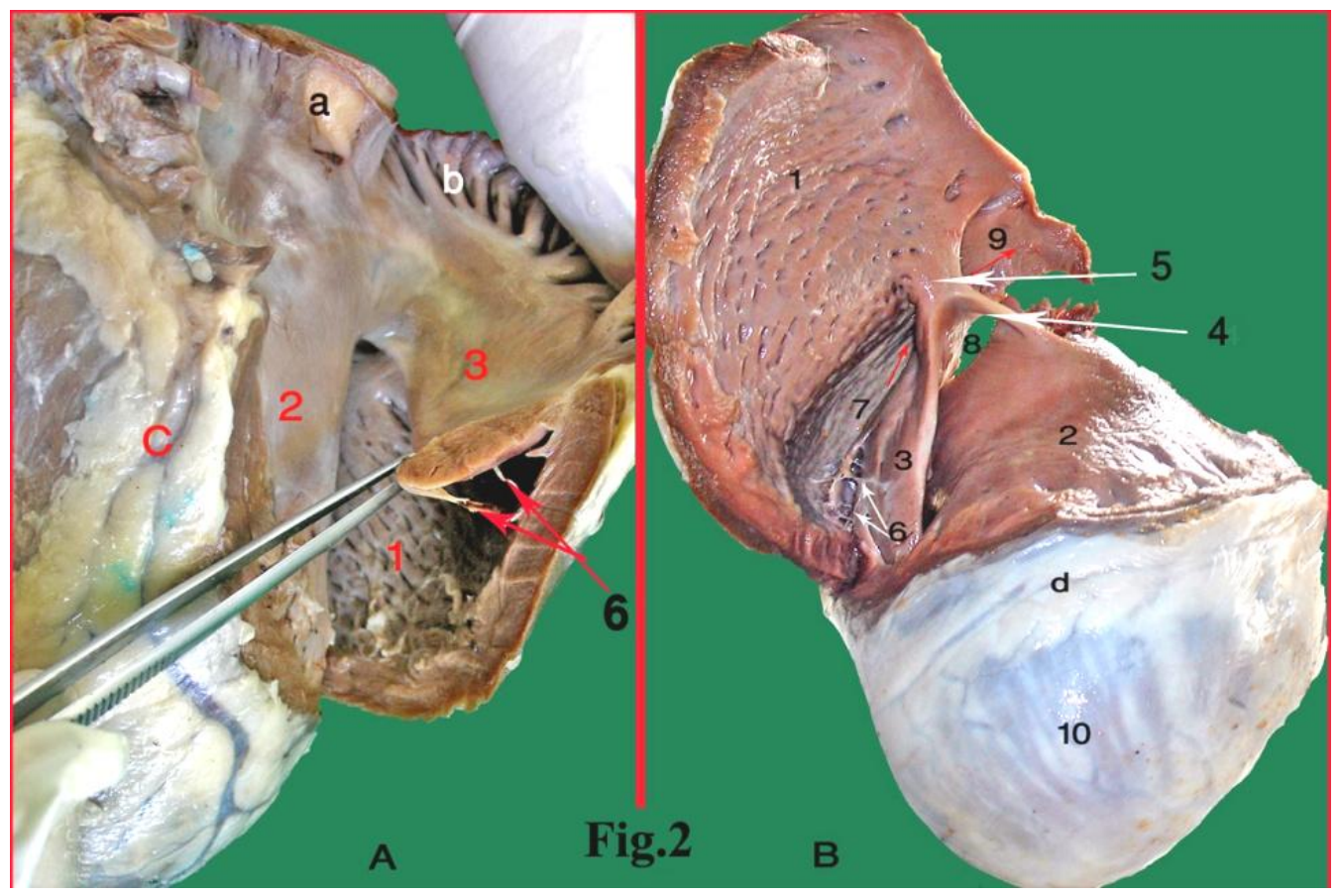

Figure (2): Right ventricular cavity showing the right atrioventricular valve. Part A. View from the right surface. Part B. View from the left surface.

1. Right ventricular free wall. 2. Right septal wall. 3. The triangular muscular plate. 4 . Membrane fixed triangular muscular plate to septal wall.

5. Muscle bundle fixed triangular muscular plate to parietal wall. 6. Chordae tendinae.7. Cul-de-sac.

8. Right atrioventricular opening. 9. Opening between cul-de-sac and conus arteriosus. 10. Left ventricle. a. Aorta. b. Right atrial cavity. c. Subsinosal interventricular groove. d. Paraconal interventricular groove. 


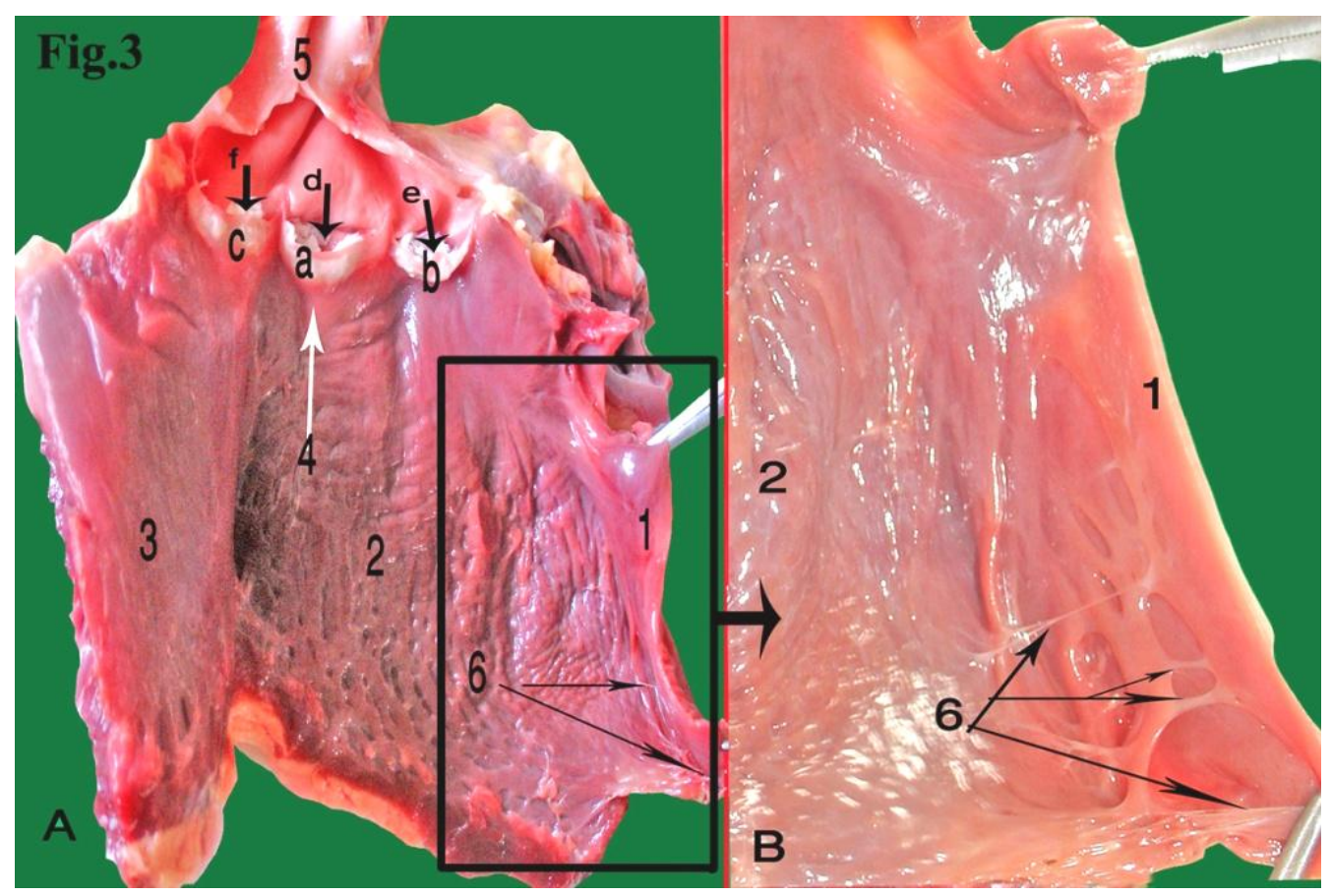

\section{Figure (3): The right atrioventricular valve.}

A The isolated right atrioventricular valve, B Enlarged area showing the triangular muscular plate.

1 The triangular muscular plate, 2 Right ventricular free wall, 3 Right septal wall, 4 Entrance of pulmonary trunk, 5 Pulmonary trunk, 6 False chordae tendinae.

a Intermediate cusp of pulmonary valve, b Right cusp of pulmonary valve, c Left cusp of pulmonary valve, $d$ Intermediate pulmonary sinus, e Right pulmonary sinus, $f$ Left pulmonary sinus. 


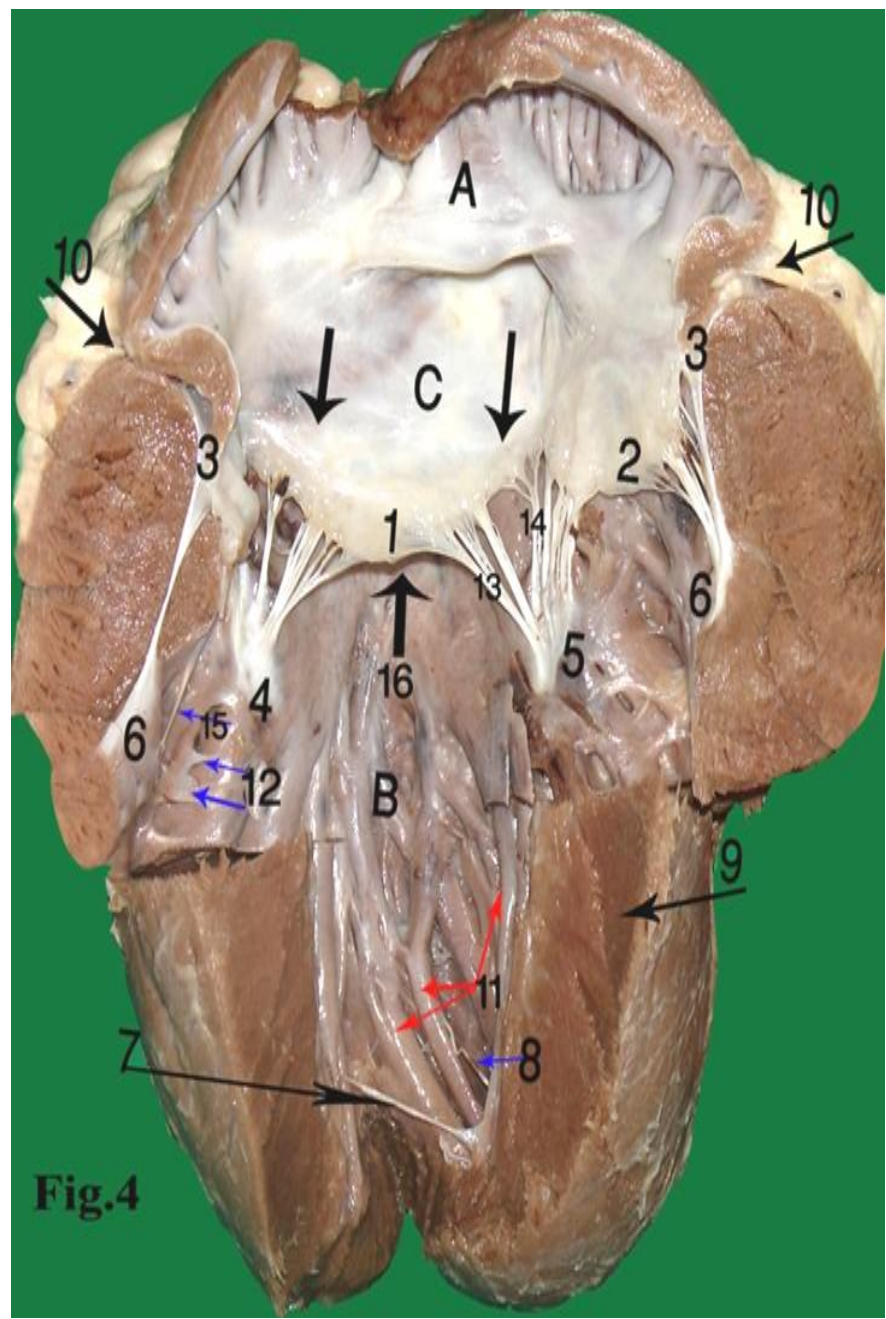

Figure (4): left ventricular cavity showing the left atrioventricular valve. A Left atrial cavity, B Left ventricular, C Left atrioventricular opening.

1 Septal cusp, 2 Right caudoparietal cusp, 3 Left cranioparietal cusp, 4 Septoparietal papillary muscle, 5 Septal papillary muscle, 6 Parietal papillary muscle, 7 Septomarginal false chordae tendinae, 8 Intraseptal false chordae tendinae, 9 Left ventricular free wall, 10 Coronary groove, 11 Trabeculae carneae, 12 Intraparietal false chordae tendinae, 13 True chordae tendinae, 14 Commissural true chordae tendinae, 15 Papillaromarginal false chordae tendinae, 16 Entrance of aortic vestibule. 


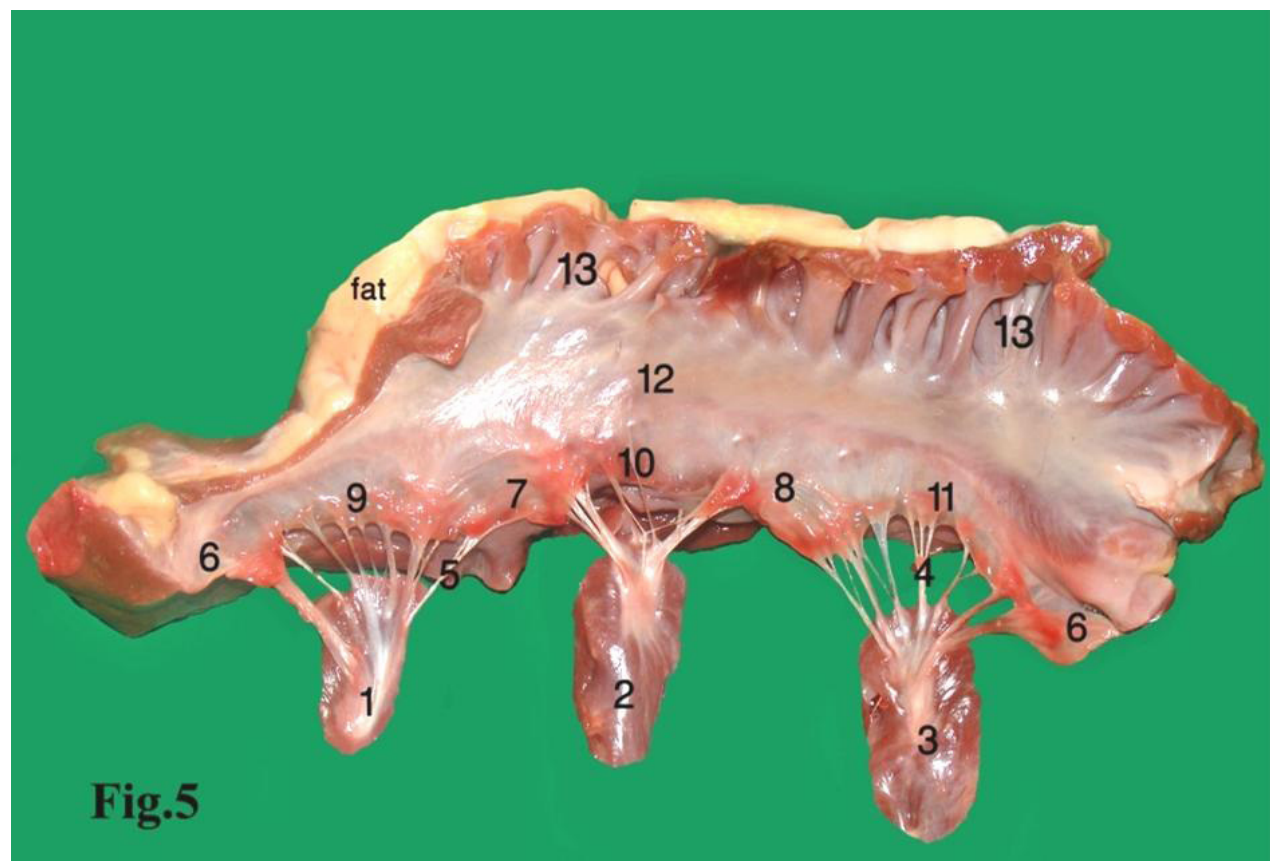

Figure (5): The left atrioventricular valve.

1 Septoparietal papillary muscle, 2 Septal papillary muscle, 3 Parietal papillary muscle, 4 Commissural chordae tendinae, 5 True chordae tendinae, 6 Left cranioparietal cusp, 7 Septal cusp, 8 Right caudoparietal cusp, 9 Left (caudal) commissure, 10 Middle (septal) commissure, 11 Right (cranial) commissure, 12 Left atrioventricular opening with fibrous ring, 13 Atrial musculature. 


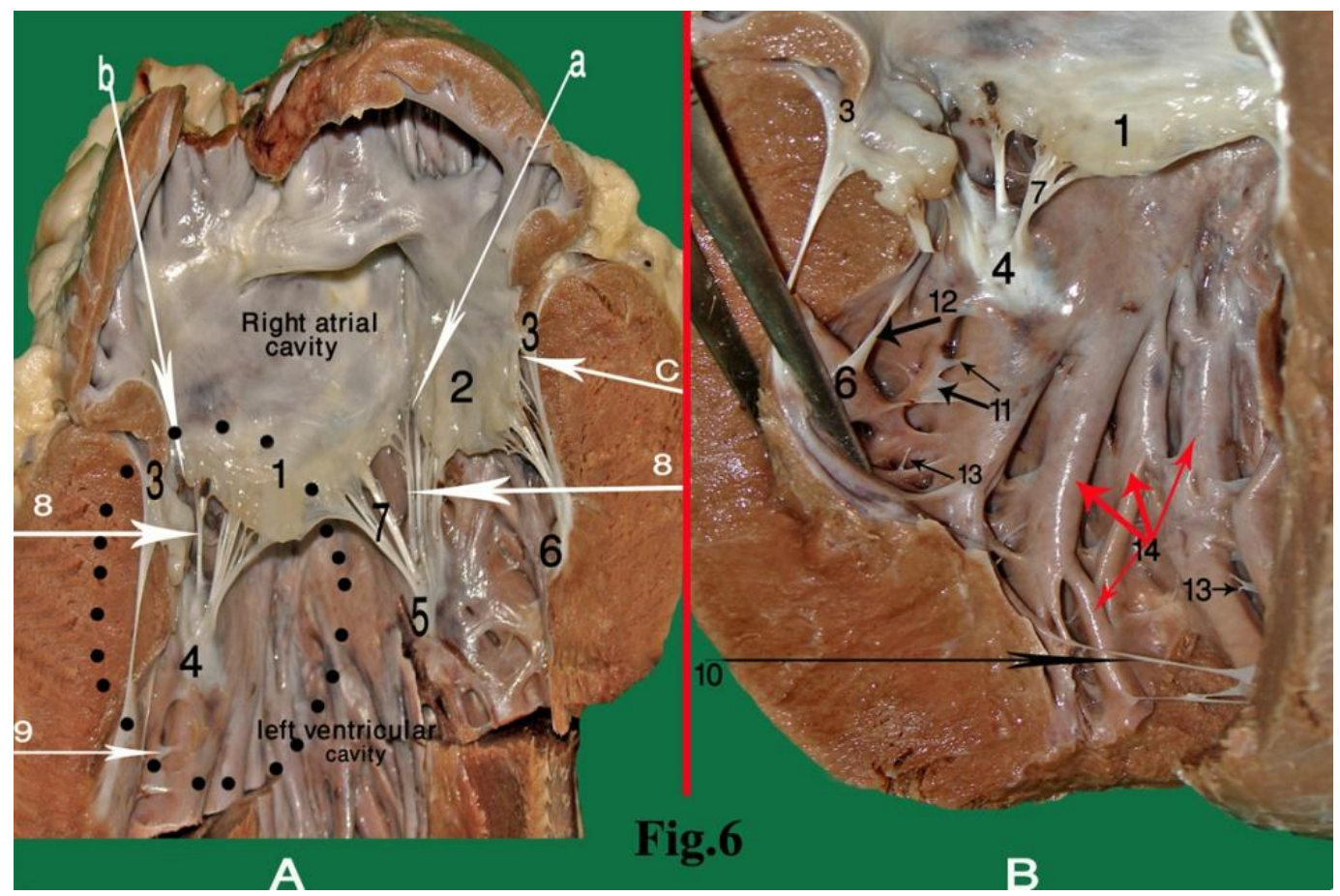

Figure (6): The left ventricular cavity. A The left ventricular cavity showing the papillary muscles, trabeculae carneae and chordae tendinae. B Enlarged dotted area.

1 Septal cusp, 2 Right caudoparietal cusp, 3 Left cranioparietal cusp, 4 Septoparietal papillary muscle, 5 Septal papillary muscle, 6 Parietal papillary muscle, 7 True chordae tendinae, 8 Commissural chordae tendinae, 9 False chordae tendinae, 10 Septomarginal false chordae tendinae, 11 Intraseptal false chordae tendinae, 12 Papillaromarginal false chordae tendinae, 13 Intraparietal false chordae tendinae, 14 Trabeculae carneae.

a middle (septal) commissure, b Left (caudal) commissure, c Right (cranial) commissure. 


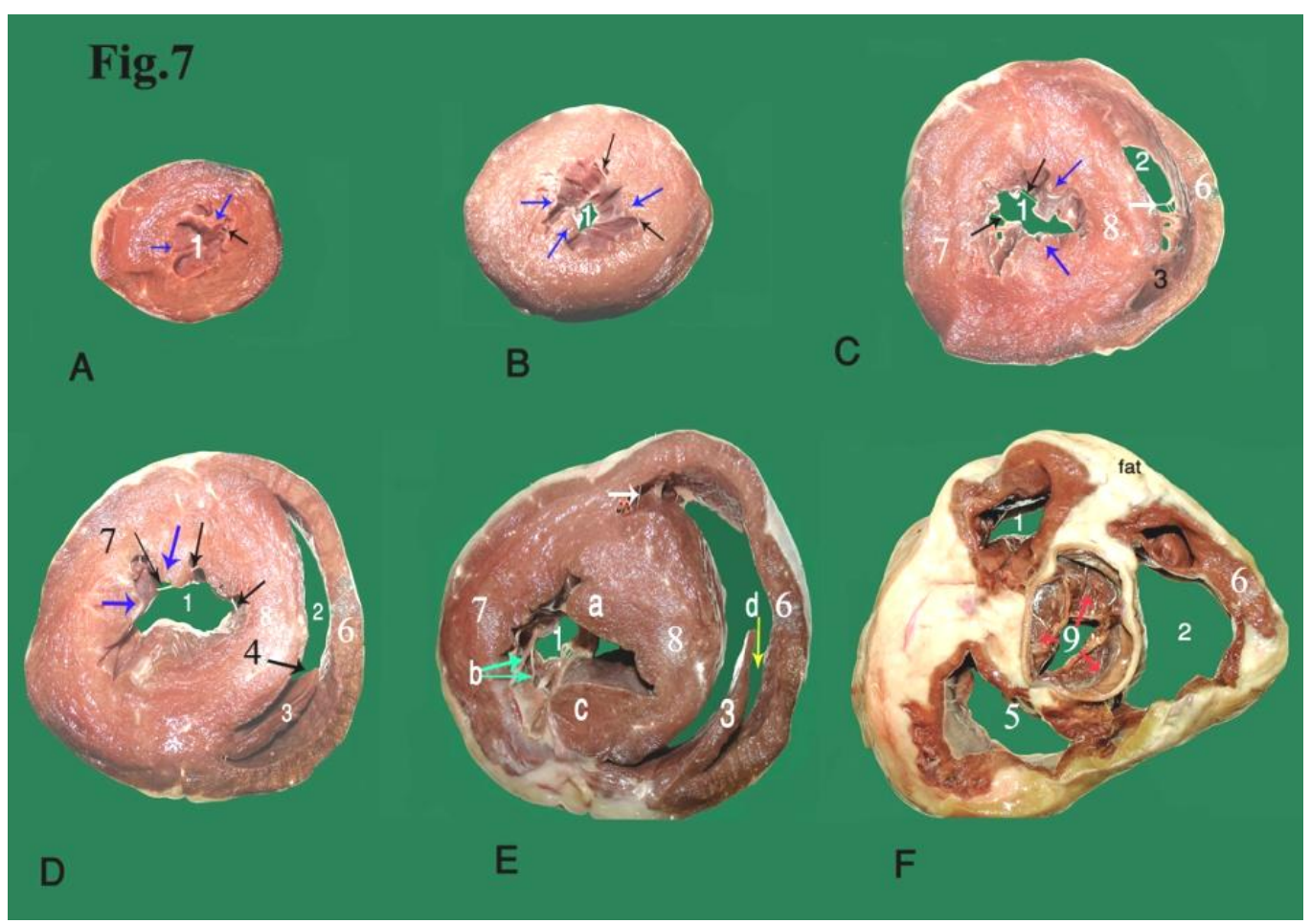

Figure (7): Cross sections of the heart (A, B, C, D, E and F).

1 Left ventricle, 2 Right ventricle, 3 The triangular muscular plate, 4 The free edge of triangular plate, 5 Pulmonary trunk, 6 Right ventricular free wall, 7 Left ventricular free wall, 8 Interventricular septum, 9 Aortic opening with its valve.

a papillary muscle, b Cusp of left atrioventricular valve, c Chordae tendinae, d Cul-desac.

White arrow refers to false chordae tendinae of left ventricle. Blue arrow refers to trabeculae carneae. Black arrow refers to false chordae tendinae of right ventricle. 


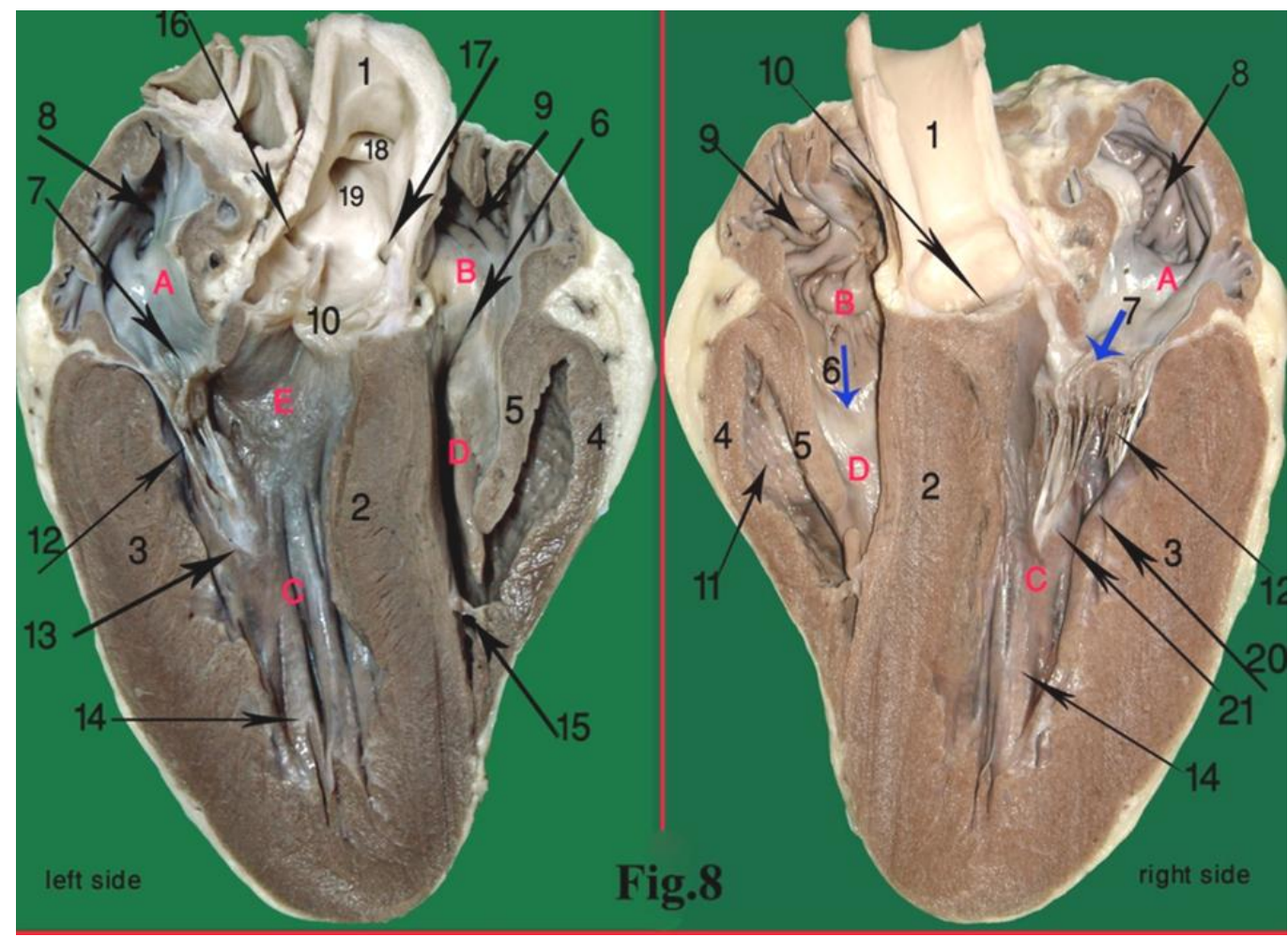

Figure (8): Sagittal section of the heart. A Left atrium, B Right atrium, C Left ventricle, D Right ventricle.

1 Aorta, 2 Interventricular septum, 3 Left ventricular free wall, 4 Right ventricular free wall, 5 The triangular muscular plate, 6 Right atrioventricular opening, 7 Left atrioventricular opening, 8 Left auricle with its pectinate muscles, 9 Right auricle with its pectinate muscles, 10 Aortic valve, 11 Cul-de-sac, 12 True chordae tendinae in left ventricle, 13 Septoparietal papillary muscle, 14 Trabeculae carneae, 15 False chordae tendinae in right ventricle, 16 Opening of left coronary artery, 17 Opening of right coronary artery, 18 Right brachiocephalic artery, 19 Left brachiocephalic artery. 